\title{
Comparison between minimally invasive, percutaneous osteosynthesis and locking plate osteosynthesis in 3-and 4-part proximal humerus fractures
}

Reinhold Ortmaier ${ }^{1 *}$, Verena Filzmaier ${ }^{2}$, Wolfgang Hitzl ${ }^{3}$, Robert Bogner ${ }^{1}$, Thomas Neubauer ${ }^{4}$, Herbert Resch $^{1}$ and Alexander Auffarth ${ }^{1}$

\begin{abstract}
Background: The ideal method for the surgical treatment of proximal humeral fractures has not yet been found. We therefore conducted a retrospective matched-pair analysis and compared osteosynthesis with open reduction and internal fixation and that with an angular stable plate with minimally invasive, closed reduction, percutaneous fixation with the Humerusblock.

Methods: During a study period of 3 years, we matched 30 patients treated with angular stable plates (group 1) for age, gender, fracture type and handedness (dominant or nondominant) to 30 patients treated using the Humerusblock (group 2). At a minimal follow-up of 24 months, clinical evaluation included the Constant-Murley score, the UCLA score and the Simple Shoulder Test. Subjective pain was evaluated using the VAS pain scale. Patients were asked to rate their subjective satisfaction of final outcome as excellent, good, satisfied or dissatisfied.

Results: The mean CMS, UCLA score and SST differed significantly between groups 1 and 2 (60.9 vs 71.9, $p<0.01$ ), ( 25.1 vs $29.5, p<0.01)$ and $(8.1$ vs $9.4, p<0.05)$, respectively. The VAS pain score was significantly lower in group 2 than in group 1 ( 1.2 vs $2.4 ; p<0.01)$.

The mean abduction $\left(109.7^{\circ}\right.$ vs $\left.133.7^{\circ} ; p<0.01\right)$ and anterior flexion $\left(128.3^{\circ}\right.$ vs $\left.145.7^{\circ} ; p<0.01\right)$ were significantly worse in group 1. The mean operation time was significantly shorter in group $2(117.3$ vs $72.1, p<0.01)$. Complications occurred in $30 \%$ (group 1) and $23 \%$ (group 2) of patients.

Conclusions: In this study, the functional outcome is superior in the Humerusblock group. However, the general outcome after surgical treatment of 3-and 4-part fractures is moderate, and the complication rate has to be considered, even though it can be lowered with the use of minimally invasive implants.
\end{abstract}

Keywords: Proximal humeral fractures, Locking plate, Percutaneous pin fixation, Humerusblock

\section{Background}

Proximal humeral fractures (PHF) make up $5 \%$ of all fractures [1]. Due to demographic changes in western countries, not only will the absolute number of PHF increase [2,3] but also the number of complex PHF, due to an increased number of older patients with osteoporotic fractures [4]. Displaced and comminuted 3-and 4-part

\footnotetext{
* Correspondence: r.ortmaier@gmail.com

${ }^{1}$ Department of Traumatology and Sports Injuries, Paracelsus Medical University, Müllner Hauptstraße 48, A-5020 Salzburg, Austria Full list of author information is available at the end of the article
}

fractures are challenging for the surgeon, and no clear consensus for the best treatment strategy for each patient exists. Operative treatment comprises osteosynthesis and arthroplasty. Options for osteosynthesis range from locking plate fixation to intramedullary nailing, percutaneous pin fixation or the use of the Humerusblock [1, 5-8]. Currently, the workhorse for displaced 3-and 4-part proximal humeral fractures is open reduction and internal fixation using locking plate osteosynthesis. Biomechanical and clinical studies have shown high stabilities and union rates after locking plate procedures $[6,9,10]$. 
However, unsatisfactory complication rates of up to $40 \%$, after locking plate osteosynthesis show that the ideal joint-preserving method for treating proximal humeral fractures has not yet been found [11]. The Humerusblock is a k-wire based implant consisting of two locked, crossed k-wires, which allow for the minimally invasive, closed reduction and internal fixation of proximal humeral fractures. Although previous studies have shown that the Humerusblock provides all of the advantages of a minimally invasive device, high rates of pin perforation and high implant removal rates have been observed [8, 12-15].

In this retrospective, matched-pair analysis, we set out to compare the clinical and radiological results of open reduction and internal fixation using angular stable plating, with those of minimally invasive, semi-rigid, Humerusblock osteosynthesis.

\section{Patients and methods}

The study was reviewed and approved by the hospital institutional review board (Ethikkommission für das Bundesland Salzburg). Written informed consent was obtained from all the patients for the publication of this study. Consent to publish personal details in Tables 2, 3 and 4 was obtained from all participants.

From 2009 to 2012, 291 patients underwent osteosynthesis for proximal humeral fractures using either the PHILOS Plate (Synthes, Oberdorf, Switzerland) or the Humerusblock (Synthes, Oberdorf, Switzerland). 139 patients were treated with PHILOS plate, and 152 were treated with the Humerusblock. In our institutions, the PHILOS plate and the Humerusblock are used. Usage of either implant depends on the preference of the surgeon. The Humerusblock can be used for subcapital and intraarticular humeral fractures (AO/OTA classification A3, B1-3, C1-3). Due to its design, the only limitation of the Humerusblock is the use in AO A2 metaphyseal fractures with fractures level extending far below the surgical neck (Fig. 1). Use of either the PHILOS plate or the Humerusblock was decided by the surgeons with the patient and was not randomized or blinded. Demographic data were used to retrospectively review a prospectively gathered database of the 291 patients treated with either the PHILOS plate or the Humerusblock to perform a matched-pair analysis. Patients were matched for age (within $+/-3$ years), gender, handedness (dominant or non-dominant), affected side and fracture type (3-or 4-part proximal humeral fracture by Neer's classification system) [16]. The matching procedure was blinded to the outcome. The minimum follow-up was 24 months after surgery. Exclusion criteria were head-split fractures, lesions of the brachial plexus, pathologic fractures, dementia, previous surgery on the affected shoulder, heavy tobacco abuse, alcohol abuse or steroid intake.

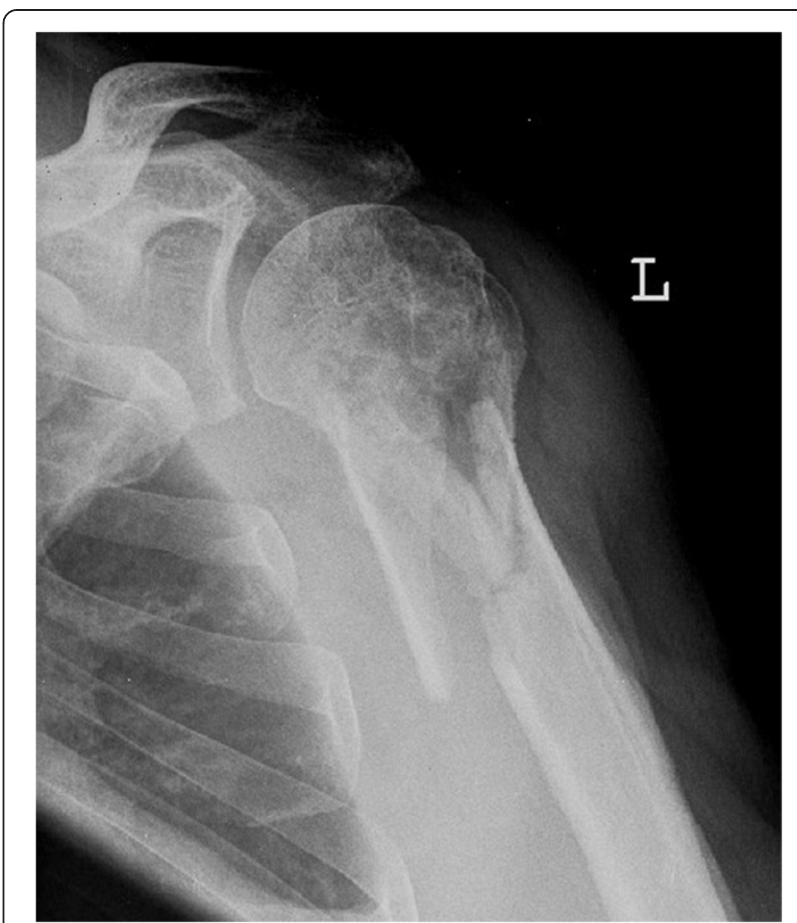

Fig. 1 Limitation of the Humerusblock. The long metaphyseal fracture line reaching far below makes it impossible to stabilize the fracture with the Humerusblock

86 Patients (43/group) fulfilled the matching criteria and were contacted to return for clinical and radiological evaluation. Of those, 15 died and 11 did not return for evaluation.

Therefore, 30 patients treated using the PHILOS plate were matched to 30 Humerusblock patients according to the matching criteria. In both groups, there were 20, 4-part fractures and 10, 3-part fractures.

Group 1 (PHILOS) comprised 30 patients (17 female, 13 men) with a mean age of 61.3 years (range, 36-80 years). Group 2 (HB) also comprised 30 (17 female, 13 men) patients with a mean age of 61.7 years (range, 37-78 years). Table 1 shows details of the matched pairs. Figures 2 and 3 show an example of a matched-pair analysis, and Table 2 shows the demographics and outcomes of the example.

\section{Surgical technique}

All of the procedures on patients in both groups were performed in the beach chair position. General anesthesia in combination with an interscalene block were used in all procedures, and all patients received perioperative intravenous antibiotic prophylaxis. In group 1, (PHILOS) a deltopectoral approach was used in all of the patients. First, the tuberosities were tagged with non-absorbable number 2 or 3 sutures behind the rotator cuff insertion. Then, the humeral head was reduced and fixed with k-wires. The 
Table 1 Patient demographics

\begin{tabular}{|c|c|c|c|}
\hline & Group1 & Group2 & Overall \\
\hline Age (range) & $61.3(36-80)$ & $61.7(37-78)$ & $61.5(36-80)$ \\
\hline \multicolumn{4}{|l|}{ Gender } \\
\hline Male & 13 & 13 & 26 \\
\hline Female & 17 & 17 & 34 \\
\hline \multicolumn{4}{|l|}{ Handedness } \\
\hline right & 23 & 23 & 26 \\
\hline left & 7 & 7 & 14 \\
\hline \multicolumn{4}{|l|}{ Side (injured arm) } \\
\hline right & 18 & 18 & 36 \\
\hline left & 12 & 12 & 24 \\
\hline OR time min (range) & $117.3(77-208)$ & $72.1(31-206)$ & $94.7(31-208)$ \\
\hline \multicolumn{4}{|l|}{ Accident } \\
\hline Low energy (home fall, pedestrian) & 23 & 17 & 40 \\
\hline Traffic (bike, motorcycle, car) & 7 & 13 & 20 \\
\hline \multicolumn{4}{|l|}{ ASA } \\
\hline 1 & 8 & 10 & 18 \\
\hline 2 & 17 & 13 & 30 \\
\hline 3 & 5 & 7 & 12 \\
\hline \multicolumn{4}{|l|}{ Fracture type } \\
\hline 4 part & 20 & 20 & 40 \\
\hline 3 part & 10 & 10 & 20 \\
\hline valgus & 17 & 17 & 34 \\
\hline varus & 13 & 13 & 26 \\
\hline
\end{tabular}

PHILOS plate was then adapted, and the tuberosities were reduced by tying them together over the plate. The PHILOS plate was temporarily secured at the humeral shaft with k-wires, and a non-locking screw was introduced through the plate in the shaft. Holes for the head screw were made by subchondral drilling under fluoroscopy control in order to avoid perforating the joint. Before the end of surgery, the final result was assessed by fluoroscopy.

The Humerusblock is made of stainless steel and is made for the fixation of $2 \mathrm{k}$-wires up to $2.5 \mathrm{~mm}$ in diameter (Fig. 4). The 2 lateral canals for the k-wires are at an angle of $35^{\circ}$ at the lower plane of the implant and at a $25^{\circ}$ angle to each other, which makes the k-wires cross over and diverge in the humeral head. The $\mathrm{k}$-wires are locked in the Humerusblock by small pins. The Humerusblock itself is secured at the shaft by a $3.5 \mathrm{~mm}$ selftapping screw at the shaft.

The Humerusblock is inserted via a $3 \mathrm{~cm}$ skin incision at the lateral aspect of the upper arm, approximately $5 \mathrm{~cm}$ distal to the subcapital fracture level. The Humerusblock is fixed to the shaft with a self-tapping cannulated $3.5 \mathrm{~mm}$ screw. Two $2.5 \mathrm{~mm}$ k-wires are introduced into the shaft up to the fracture level in the so-called "waiting position". Then, the closed reduction under manual traction and fluoroscopy control is performed. The surgeon holds the arm and reduces the fracture, and the assistant drills the $\mathrm{k}$-wires to the subchondral level. The reduction of the tuberosities and/or the lifting or derotating of the head is performed via small skin incision using hooks and elevators, as seen in Fig. 5. Tuberosities are percutaneously fixed using $2.7 \mathrm{~mm}$ or $3.0 \mathrm{~mm}$ cannulated screws. Finally, the two $2.5 \mathrm{~mm}$ k-wires are tightened and a few millimeters are cut off of the Humerusblock.

\section{Postoperative rehabilitation}

Patients in group 1 were treated with immobilization of the shoulder in a sling for 2 weeks. Active finger, wrist and elbow movement was allowed on the first postoperative day, and pendulum exercises of the shoulder were started at least 14 days postoperatively. Active abduction up to $90^{\circ}$ was started after the sling was removed, depending on surgeon-specified guidelines. Heavy manual work and resistive exercises were allowed 8 to 12 weeks postoperatively.

The postoperative rehabilitation protocol of patients in group 2 included wearing a shoulder sling for 4 weeks. Finger and elbow movements were allowed immediately postoperatively. Active abduction and anterior elevation 


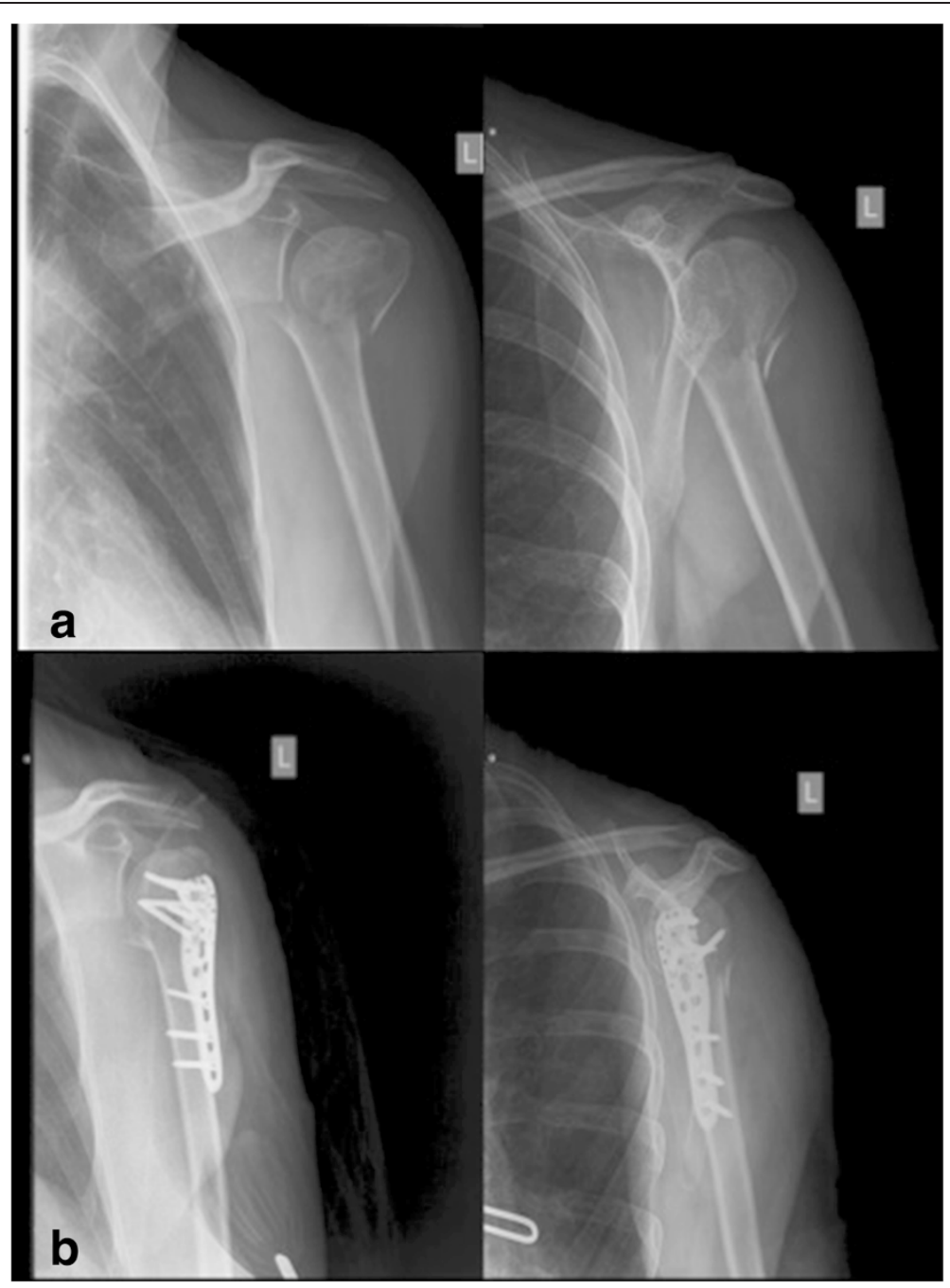

Fig. 2 A valgus, impacted 3-part fracture of a left shoulder treated using the PHILOS plate $\mathbf{a}$. X-rays in 2 planes postoperatively $\mathbf{b}$. Matching criteria and outcome are illustrated in Table 2

were allowed after sling removal, while load-bearing and heavy manual work was allowed after 10-12 weeks.

\section{Data collection/clinical and radiological evaluation}

The Constant-Murley score (CMS) [17], the UCLA score [18] and the Simple Shoulder Test (SST) [19] were determined. The Constant-Murley score includes the pain score, functional assessment, range of motion and strength measurement with a maximum score of 100 points. The UCLA score includes pain, function, satisfaction and strength with a maximum score of 35 points. The Simple Shoulder Test comprises 12 yes-or no-response questions to objective and subjective items. The visual analog pain scale (VAS) [20] was used to rate the patient's subjective pain. Range of motion was measured using a goniometer. The patients were also asked to rate their subjective satisfaction at the final follow-up as either excellent, good, satisfied or dissatisfied.
The clinical evaluation was performed by one independent examiner (OR) who was not part of the surgical team.

Radiological evaluation included an X-ray of the affected shoulder in at least 2 standard projections anteroposterior (AP) and axial and/or Y views. The $\mathrm{X}$-ray evaluation was focused on malreduction, malunion, nonunion, AVN, loss of reduction and screw or pin perforation.

\section{Statistical analysis}

Data consistency was checked and data were screened for outliers and normality by using quantile plots. Paired Student's t-tests were used to compare variables between groups. All reported tests were two-sided, and $p$-values $<$ 0.05 were considered to be statistically significant. All statistical analyses in this report were performed with STATISTICA 10 (Hill, T. \& Lewicki, P. Statistics: Methods and Applications. StatSoft, Tulsa, OK). 


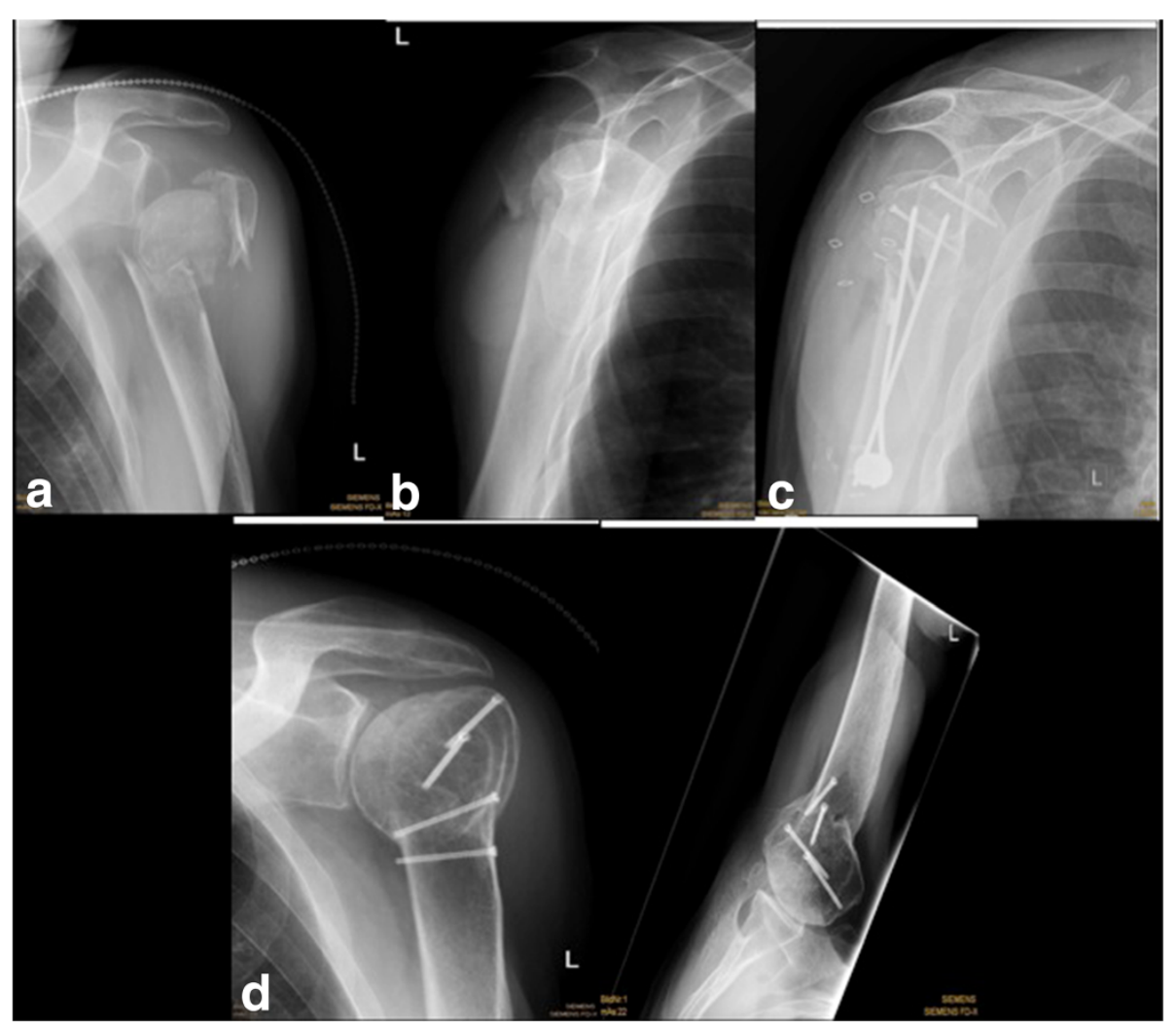

Fig. 3 A valgus, impacted 3-part fracture of a left shoulder treated using the Humerusblock $\mathbf{a}, \mathbf{b}$. X-ray postsurgical after Humerusblock c. X-rays in 2 planes at final follow-up after 40 months $\mathbf{d}$. Matching criteria and outcome are illustrated in Table 2

\section{Results}

\section{Group 1 PHILOS plate}

After a mean follow-up of 38.4 months (range, 26-56 months), patients scored 60.9 points (range, 15-87) on the CMS. The mean UCLA score was 25.1 points (range, 15-35), and the mean SST was 8.1 points (range, 1-12), respectively. The mean abduction was $109.7^{\circ}$ (range, 40-170),

Table 2 An example of two matched patients

\begin{tabular}{lll}
\hline & patient group 1 & patient group 2 \\
\hline gender & female & female \\
age & 62 & 64 \\
handedness & left & left \\
affected arm & left & left \\
fracture type & Valgus impacted 3-part & Valgus impacted 3-part \\
accident & bike & Home fall \\
ASA & 2 & 2 \\
operation time & 102 min & 71 min \\
CMS & 60 & 80 \\
UCLA & 22 & 26 \\
SST & 6 & 8 \\
VAS & 3 & 1 \\
\hline X-rays of the matched & &
\end{tabular}

X-rays of the matched patients are illustrated in Fig. 1 and 2 and mean anterior flexion was $128.3^{\circ}$ (range, 40-170). The mean VAS pain score was 2.4 (range, $0-7)$. The mean operation time was $117.3 \mathrm{~min}$ (range, 77-208).

At final follow-up, 7 patients rated their outcome as excellent, 5 as good, 10 as satisfied and 8 as dissatisfied.

Complications (Table 3 ) occurred in $30 \%$ of patients (9 patients). In 5 patients, (17 \%) secondary screw cut-out due to varus collapse was seen; of those, 5 patients were treated with reosteosynthesis at 6, 8, 10, 11 and 12 weeks after initial surgery.

Four patients (13\%) showed signs of avascular necrosis of the head. Presently, the 4 patients refuse to undergo shoulder arthroplasty. Implant removal was performed in 12 (40\%) of the patients after bony healing.

\section{Group 2 humerusblock}

The mean follow-up of patients in group 2 was 36.1 months (range, 25-50 months). The mean CMS score was 71.9 points (range, 34-88). The mean UCLA score was 29.5 points (range, 17-34), and the mean SST was 9.4 points (range, 4-12), respectively. The mean abduction was $133.7^{\circ}$ (range, 50-170), and mean anterior flexion was $145.7^{\circ}$ (range, 60-180). The mean VAS pain score was 1.2 (range, 0-6). The mean operation time was $72.1 \mathrm{~min}$ (range, 31-206). 


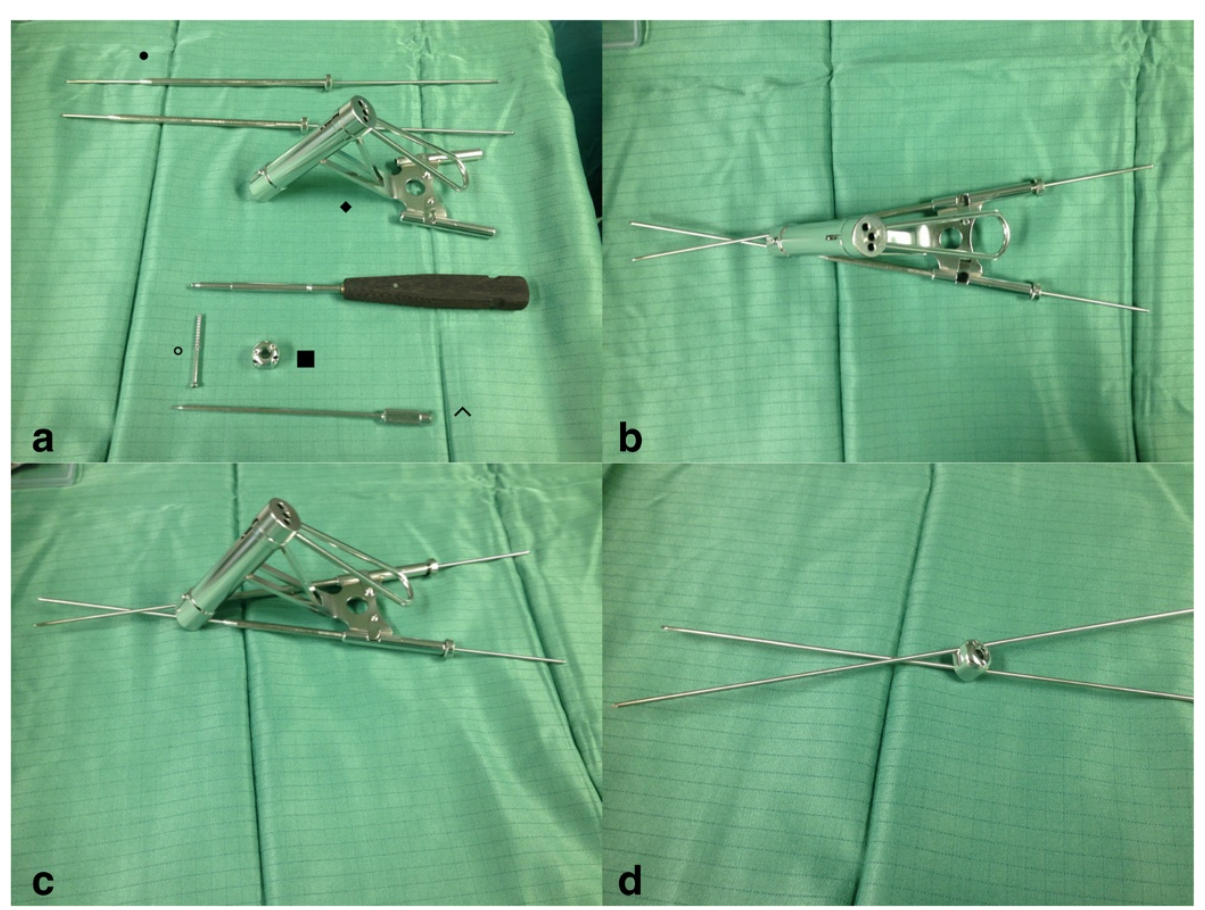

Fig. 4 The Humerusblock implant and instruments.a shows • Kirschner-wire centering sleeve with two 2.5 mm Kirschner wires. Insertion guide and drill sleeve for Humerusblock. Humerusblock with two offset canals for the Kirschner wires and two headless pins for locking the Kirschner wires in the Humerusblock. ${ }^{\circ} 3.5 \mathrm{~mm}$ self-tapping cortex screw to fix the Humerusblock to the lateral aspect of the humeral bone. ${ }^{\wedge}$ Special screw driver for Humerusblock to fix the headless pins.b shows Humerusblock insertion guide together with Kirschner-wire centering sleeve and two $2.5 \mathrm{~mm}$ Kirschner wires. c shows Humerusblock insertion guide, Kirschner-wire centering sleeve and Kirschner wires from lateral. $\mathbf{d}$ Kirschner wires crossing over at an angle of $25^{\circ}$ through the Humerusblock

At final follow-up, 10 patients rated their outcome as excellent, 6 as good, 10 as satisfied and 4 as dissatisfied.

Postoperative complications (Table 4) occurred in 7 patients $(23 \%)$. Three patients $(10 \%)$ had a loss of reduction. Reosteosynthesis was performed 1, 2 and 3 weeks postoperatively. Of those who received reosteosynthesis, 1 patient was dissatisfied, and the other two were satisfied at the final follow-up. The dissatisfied patient had a CMS score of 54 points, and the satisfied patients had CMS scores of 60 and 64 points. Two patients $(7 \%)$ showed signs of AVN at the final follow-up. Presently, neither of these two patients wants additional surgery. $2(7 \%)$ patients underwent retrieval of the pins due to pin perforation with the pin tips aimed at the glenoid surface.

None of the patients with pin perforation experienced delayed healing or were dissatisfied at the final followup. Implant removal was performed in 16 (42\%) of the patients after bony healing.

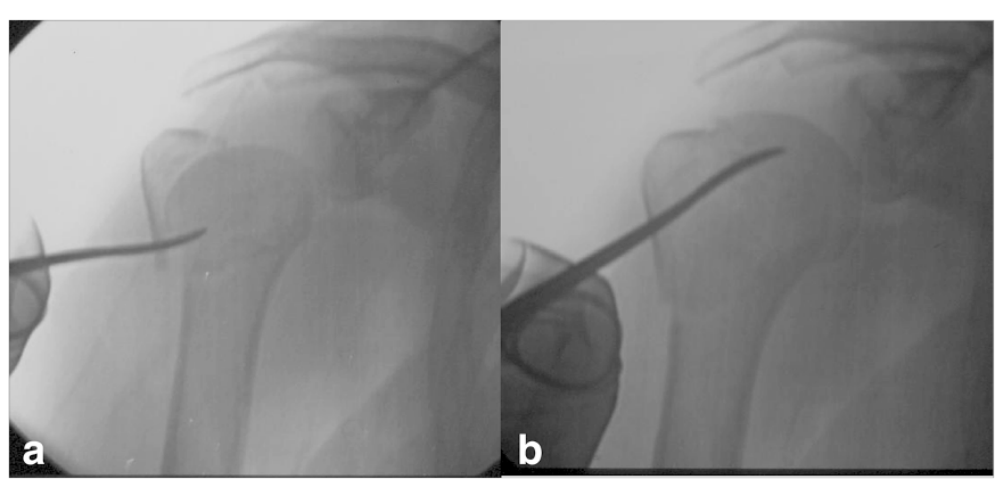

Fig. 5 An elevator is introduced into the fracture gap via a small skin incision to reduce the head by lifting it $\mathbf{a}, \mathbf{b}$ 
Table 3 Complications and outcome after treatment using the PHILOS plate

\begin{tabular}{|c|c|c|c|c|c|c|c|c|c|c|c|}
\hline Patient & Gender & Age & Fracture type & ASA & Type & $\begin{array}{l}\text { Reoperation (weeks after } \\
\text { fracture treatment) }\end{array}$ & CMS & UCLA & SST & VAS & Satisfaction \\
\hline 1 & male & 75 & 4 part & 2 & Screw cut out & 6 & 54 & 25 & 7 & 4 & $\overline{\text { dissatisfied }}$ \\
\hline 2 & female & 70 & 4 part & 2 & Screw cut out & 8 & 50 & 18 & 7 & 1 & satisfied \\
\hline 3 & male & 62 & 4 part & 3 & Screw cut out & 10 & 45 & 22 & 6 & 3 & dissatisfied \\
\hline 4 & female & 71 & 3 part & 2 & Screw cut out & 11 & 51 & 29 & 7 & 1 & satisfied \\
\hline 5 & female & 74 & 4 part & 2 & Screw cut out & 12 & 50 & 25 & 8 & 3 & dissatisfied \\
\hline 6 & female & 78 & 4 part & 3 & AVN & & 44 & 24 & 7 & 7 & dissatisfied \\
\hline 7 & female & 67 & 3 part & 3 & AVN & & 15 & 13 & 1 & 7 & dissatisfied \\
\hline 8 & female & 80 & 4 part & 2 & AVN & & 30 & 15 & 5 & 3 & dissatisfied \\
\hline 9 & female & 75 & 4 part & 3 & AVN & & 37 & 15 & 4 & 3 & dissatisfied \\
\hline
\end{tabular}

\section{Comparison of the groups}

The mean functional outcome scores (CMS, UCLA and SST) differed significantly between groups 1 and 2: (60.9 vs $71.9, p<0.01)$, (25.1 vs $29.5, p<0.01)$ and ( 8.1 vs 9.4 , $p<0.05)$, respectively. The mean abduction $\left(109.7^{\circ}\right.$ vs $\left.133.7^{\circ} ; p<0.01\right)$ and anterior flexion $\left(128.3^{\circ}\right.$ vs $145.7^{\circ}$; $p<0.01)$ was significantly worse in group 1 .

The VAS pain score was significantly lower in group 2 compared to group 1 ( 1.2 vs $2.4 ; p<0.01)$. The mean operation time differed significantly between the groups (117.3 vs $72.1, p<0.01)$.

\section{Discussion}

Currently, angular stable plating is widely used in osteosynthesis for the treatment of complex 3-and 4-part fractures of the proximal humerus [10]. Despite many reports showing considerably improved results after angular stable plating, complication rates higher than $40 \%$ are reported [10]. This give rise to the idea that the ideal method for treatment of 3-and 4-part PHFs has not been found. In this study, we found the functional results and postoperative pain according CMS, UCLA score, SST and visual analogue pain scale were significantly better after the use of the Humerusblock than after that of the PHILOS angular stable plate. According to a systemic review analyzing results after angular stable plating, a mean CMS score of 72 points for 3-part fractures and
66 points for 4-part fractures were reported [10]. Those results are slightly better than our results of a mean CMS score of 60.9 points.

Range of motion seems to be very important especially for older people in order to manage their activities of daily living. For this reason, in older patients, perhaps it is more important to restore range of motion than strength. Surprisingly, only a few studies specifically report on range of motion after plating [10]. However, in this study, abduction and anterior flexion were found to be significantly better in the Humerusblock group than in the PHILOS plate group.

There are only a few reports of results after the use of the Humerusblock [8, 12, 13]. Brunner et al. [13] analyzed in a prospective case series 58 patients with a mean CMS of 73.6 points, abduction of $107^{\circ}$ and anterior flexion of $119.2^{\circ}$. Bogner et al. [8] found in 51 3-and 4-part fractures after a mean follow up of 33.8 months, a mean CMS of 61.2 points for 3-part and 49.5 points in 4-part fractures in elderly patients, with a mean overall CMS of 71.6 points and abduction and anterior flexion of $133^{\circ}$ and $143.5^{\circ}$. Therefore, our results are in line or even slightly better than the results reported in the literature.

Complication rates after angular stable plating up to $49 \%$ [10] and reoperation rates up to $44 \%$ [21] are reported. The most common complications are screw

Table 4 Complications and outcomes after treatment using the Humerusblock

\begin{tabular}{|c|c|c|c|c|c|c|c|c|c|c|c|}
\hline Patient & Gender & Age & Fracture type & ASA & Type & $\begin{array}{l}\text { Reoperation (weeks after } \\
\text { fracture treatment) }\end{array}$ & CMS & UCLA & SST & VAS & Satisfaction \\
\hline 1 & female & 70 & 4 part & 2 & loss of reduction & 1 & 54 & 21 & 8 & 4 & $\overline{\text { dissatisfied }}$ \\
\hline 2 & female & 54 & 4 part & 2 & loss of reduction & 2 & 60 & 27 & 9 & 2 & satisfied \\
\hline 3 & male & 62 & 4 part & 3 & loss of reduction & 3 & 64 & 28 & 9 & 2 & satisfied \\
\hline 4 & female & 48 & 3 part & 2 & pin perforation & 2 & 70 & 30 & 10 & 0 & satisfied \\
\hline 5 & male & 67 & 4 part & 3 & pin perforation & 3 & 60 & 21 & 8 & 4 & dissatisfied \\
\hline 6 & female & 72 & 4 part & 2 & AVN & & 48 & 18 & 8 & 5 & dissatisfied \\
\hline 7 & female & 78 & 4 part & 2 & AVN & & 34 & 17 & 4 & 6 & dissatisfied \\
\hline
\end{tabular}


perforations with rates between $8 \%-20 \%$, avascular necrosis between $10 \%-33 \%$, loss of fixation up to $16 \%$, impingement up to $6 \%-11 \%$ and infection between $4 \%-19 \%[10,21]$. In this study, we found complication and reoperation rates of $30 \%$ for patients treated with the PHILOS plate and $23 \%$ for the Humerusblock. Radiologic signs of AVN were found in 4 patients in the PHILOS group and in 2 in the Humerusblock group. Occurrence of AVN is influenced not only by surgical factors but also by nonsurgical factors, such as fracture type, medial hinge, short calcar fragment or head split fracture, as well as the comorbidities of the patient [22]. However, nonanatomical reduction and extended soft tissue dissection are suggested to promote AVN development [22, 23]. The Humerusblock is removed from the fracture zone without harming soft tissue in the injured area. Reduction is performed in a closed or percutaneous manner, thus preserving remaining periosteal bridges between fracture fragments and reducing the risk of $\operatorname{AVN}[8,12,13]$. Unlike pin perforation after treatment using the Humerusblock, screw cut-out after angular stable plating is a serious complication [11]. In the literature, screw perforations seem to be one of the most frequent complications after plating, with reported rates up to $20 \%[11,24]$. In a study by Jost et al. [11], $57 \%$ of patients with screw perforations showed glenoid destruction, and this represents a devastating complication. In our study, 5 patients with screw perforations needed reosteosynthesis. In contrast to screw perforation, in angular stable plating, pin perforation after treatment using the Humerusblock, as long as the tips of the k-wires do not aim at the glenoid surface, is considered a minor complication. Quite to the contrary, the Humerusblock allows for the dynamic stabilization and controlled sintering and fracture consolidation of the head fragment. In this study, pin perforation occurred in 2 patients $(7 \%)$, but rates up to $41 \%$ are reported in the literature [14]. In the studies by Brunner et al. [13] and Bogner et al. [8], secondary impaction of the head leads to k-wire perforation in $22 \%$ and $10 \%$ of patients, respectively. Pin perforation can be easily detected in standard $\mathrm{x}$-rays. Treatment is simple and doesn't influence final outcome or bony healing [13]. If pin perforation occurs before bony healing and the k-wires aim at the glenoid surface, retrieval at the subcortical level is performed under local anesthesia. If the k-wires don't aim at the glenoid surface, immediate $\mathrm{k}$-wire removal after bony healing and before sling removal is performed. In general, the Humerusblock is not required to be removed. As mentioned, such as in angular stable plates, only in cases of $\mathrm{k}$-wire perforation or due to the wish of the patient should the Humerusblock be removed.

Loss of reduction is a well-known complication after osteosynthesis of complex 3-and 4-part fractures $[10,11,21]$. In this study, a loss of reduction was observed in 3 patients after treatment using the Humerusblock and in 5 patients after treatment using the PHILOS plate. In the Humerusblock group, all 3 patients were successfully treated with reosteosynthesis using the Humerusblock again, and 5 patients in the PHILOS group were successfully treated with reosteosynthesis using the PHILOS plate again. In angular stable plating, a loss of reduction often causes varus collapse, which leads to screw perforation. Osteoporotic bone angular stable plates may provide too much stiffness, which can lead to stress between the implant/bone interface leading to screw cut-out or micromotion under threshold for callus formation [25, 26]. However, excessively elastic implants lead to early failure. With the Humerusblock, k-wires are fixed to the block preventing migration. The semirigid design reduces peak stresses at the bone implant interface and allows the humeral head to sinter [25].

Operation time in the Humerusblock group was 45.2 minutes faster than in the PHILOS group. However, if the Humerusblock is removed after bony healing, a short, second operation is planned and performed.

This study has several limitations. Its small sample size and dropout rate of $30 \%$ as well its retrospective design may limit its validity. However, the main focus in this study was to increase the comparability of both cohorts, which is based on an exact and detailed matching process. Although, many reports about treatment of PHF and angular stable plating exist, data heterogeneity concerning patient population, fracture type and outcome measures makes it difficult to draw definitive conclusions concerning treatment suggestions [10].

In this study, we found the use of the Humerusblock in the treatment of complex 3-and 4-part fractures was superior to angular stable plating in regard to postoperative outcome, patient satisfaction and complication rate. Therefore, for us, the Humerusblock is a good, if not superior, alternative to angular stable plates in the treatment of proximal humeral fractures. However, the outcome after surgical treatment of 3-and 4-part fractures is moderate and the complication rate is high.

\section{Conclusion}

The general outcome after surgical treatment of 3-and 4part fractures is moderate and the complication rate is high. However, in this study, the functional outcome is superior, the pain lower and the operation time is faster in the Humerusblock group. For us, the better outcome can be explained by the minimally invasiveness of the implant. The reduction is performed closed or via stab incision, which leaves periosteal bridges and the fracture hematoma intact. As every surgical procedure the Humerusblock has a certain learning curve and beginners are advised to start with simple fractures. Once learned, the Humerusblock is a fast, cheap and secure technique with represents a good 
alternative to the widely used angular stable plates in the treatment of proximal humeral fractures. However, prospective, randomized controlled, multicenter trials with high numbers of participants are necessary to draw definitive conclusions.

\section{Abbreviations}

PHF: Proximal humeral fractures; AO/OTA: AO/OTA Fracture and Dislocation Classification; CMS: Constant-Murley score; UCLA score: University of California-Los Angeles Shoulder Score; SST: Simple Shoulder Test; VAS: The visual analog pain scale; AP: Anterior Posterior; AVN: Avascular necrosis; OR: Operation time; ASA: Anesthesia Physical Classification System.

\section{Competing interests}

The authors declare that they have no competing interests.

\section{Authors' contributions}

$\mathrm{RO}$ was responsible for conception, design, acquisition of data and of the drafting the manuscript. VF and RB made substantial contributions to the conception of the manuscript. WH did the statistical work and was involved in designing the study as well as interpreting the results. HR, AA and TN gave final approval of the version to be published. All authors read and approved the final manuscript.

\section{Acknowledgements}

The authors wish to thank all participants who made this study possible. No sources of funding supported this work.

\section{Author details}

1 Department of Traumatology and Sports Injuries, Paracelsus Medical University, Müllner Hauptstraße 48, A-5020 Salzburg, Austria. ${ }^{2}$ Department of Traumatology, Diakonissenkrankenhaus Schladming, Salzburgerstraße 777, A-8970 Schladming, Austria. ${ }^{3}$ Department of Biostatistics, Paracelsus Medical University, Müllner Hauptstraße 48, A-5020 Salzburg, Austria.

${ }^{4}$ Landeskrankenhaus Horn and Paracelsus Medical University, Spitalgasse 10, A-3580 Horn Salzburg, Austria.

Received: 14 May 2015 Accepted: 8 October 2015

Published online: 14 October 2015

\section{References}

1. Court-Brown CM, Caesar B. Epidemiology of adult fractures: A review. Injury. 2006:37:691-7.

2. Akhter MP, Lappe JM, Davies KM, Recker RR. Transmenopausal changes in the trabecular bone structure. Bone. 2007:41:111-6.

3. Kannus P, Palvanen M, Niemi S, Sievänen H, Parkkari J. Rate of proximal humeral fractures in older Finnish women between 1970 and 2007. Bone. 2009:44:656-9.

4. Baron JA, Barrett JA, Karagas MR. The epidemiology of peripheral fractures. Bone. 1996;18(3 Suppl):209S-13S.

5. Adedapo AO, Ikpeme JO. The results of internal fixation of three-and four-part proximal humeral fractures with the Polarus nail. Injury. 2001;32:115-21.

6. Rose PS, Adams CR, Torchia ME, Jacofsky DJ, Haidukewych GG, Steinmann SP. Locking plate fixation for proximal humeral fractures: initial results with a new implant. J Shoulder Elb Surg Am Shoulder Elb Surg Al. 2007;16:202-7.

7. Nho SJ, Brophy RH, Barker JU, Cornell CN, MacGillivray JD. Management of proximal humeral fractures based on current literature. J Bone Joint Surg Am. 2007:89 Suppl 3:44-58.

8. Bogner R, Hübner C, Matis N, Auffarth A, Lederer S, Resch H. Minimally-invasive treatment of three-and four-part fractures of the proximal humerus in elderly patients. J Bone Joint Surg (Br). 2008;90:1602-7.

9. Siffri PC, Peindl RD, Coley ER, Norton J, Connor PM, Kellam JF. Biomechanical analysis of blade plate versus locking plate fixation for a proximal humerus fracture: comparison using cadaveric and synthetic humeri. J Orthop Trauma. 2006:20:547-54.

10. Sproul RC, lyengar JJ, Devcic Z, Feeley BT. A systematic review of locking plate fixation of proximal humerus fractures. Injury. 2011:42:408-13.

11. Jost B, Spross C, Grehn H, Gerber C. Locking plate fixation of fractures of the proximal humerus: analysis of complications, revision strategies and outcome. J Shoulder Elb Surg Am Shoulder Elb Surg Al. 2013;22:542-9.
12. Resch H, Hübner C, Schwaiger R. Minimally invasive reduction and osteosynthesis of articular fractures of the humeral head. Injury. 2001;32 Suppl 1:SA25-32.

13. Brunner A, Weller K, Thormann S, Jöckel J-A, Babst R. Closed reduction and minimally invasive percutaneous fixation of proximal humerus fractures using the Humerusblock. J Orthop Trauma. 2010;24:407-13.

14. Carbone S, Moroder P, Arceri V, Postacchini R, Gumina S. The amount of humeral head impaction of proximal humeral fractures fixed with the Humerusblock device. Int Orthop. 2014;38(7):1451-9.

15. Kralinger F, Irenberger A, Lechner C, Wambacher M, Golser K, Sperner G Comparison of open versus percutaneous treatment for humeral head fracture. Unfallchirurg. 2006;109:406-10.

16. Neer 2nd CS. Displaced proximal humeral fractures. I. Classification and evaluation. J Bone Joint Surg Am. 1970;52:1077-89.

17. Constant CR, Murley AH. A clinical method of functional assessment of the shoulder. Clin Orthop. 1987;214:160-4.

18. Amstutz HC, Sew Hoy AL, Clarke IC. UCLA anatomic total shoulder arthroplasty. Clin Orthop. 1981;155:7-20.

19. Richards RR, An KN, Bigliani LU, Friedman RJ, Gartsman GM, Gristina AG, et al. A standardized method for the assessment of shoulder function. J Shoulder Elb Surg Am Shoulder Elb Surg Al. 1994:3:347-52.

20. Huskisson EC. Measurement of pain. Lancet. 1974;2:1127-31.

21. Brorson S, Rasmussen JV, Frich LH, Olsen BS, Hróbjartsson A. Benefits and harms of locking plate osteosynthesis in intraarticular (OTA Type C) fractures of the proximal humerus: a systematic review. Injury. 2012;43:999-1005.

22. Krappinger D, Bizzotto N, Riedmann S, Kammerlander C, Hengg C, Kralinger FS. Predicting failure after surgical fixation of proximal humerus fractures. Injury. 2011;42:1283-8.

23. Gardner MJ, Weil Y, Barker JU, Kelly BT, Helfet DL, Lorich DG. The importance of medial support in locked plating of proximal humerus fractures. J Orthop Trauma. 2007;21:185-91.

24. Owsley KC, Gorczyca JT. Fracture displacement and screw cutout after open reduction and locked plate fixation of proximal humeral fractures [corrected]. J Bone Joint Surg Am. 2008;90:233-40.

25. Lill H, Hepp P, Korner J, Kassi J-P, Verheyden AP, Josten C, et al. Proximal humeral fractures: how stiff should an implant be? A comparative mechanical study with new implants in human specimens. Arch Orthop Trauma Surg. 2003;123:74-81.

26. Gardner MJ, Nork SE, Huber P, Krieg JC. Less rigid stable fracture fixation in osteoporotic bone using locked plates with near cortical slots. Injury. 2010:41:652-6

\section{Submit your next manuscript to BioMed Central and take full advantage of:}

- Convenient online submission

- Thorough peer review

- No space constraints or color figure charges

- Immediate publication on acceptance

- Inclusion in PubMed, CAS, Scopus and Google Scholar

- Research which is freely available for redistribution 